\title{
Recetas contra la crisis: la movilidad transnacional de las empresas malienses de comercio informal
}

\author{
Annalisa Maitilasso*
}

\section{ReSUmen}

Expulsados del empleo asalariado, como consecuencia de la crisis económica, muchos migrantes malienses en España exploran hoy las oportunidades del comercio de productos de ocasión con su país de origen. Se trata de microempresas informales que aprovechan la creciente demanda en África de bienes procedentes de Europa a precios baratos. Estas empresas logran un resultado ambivalente. Por un lado, capitalizan las potencialidades en el contexto africano de productos llegados al final de su vida útil en Europa, por el otro, plantean un dilema ambiental debido a las carencias de los sistemas de tratamiento de desechos en estos países. Al enfocar estas iniciativas económicas, el artículo pretende asimismo reflexionar sobre la capacidad de los migrantes de encontrar estrategias para reconfigurar sus proyectos migratorios afectados por la precariedad en Europa.

\section{Palabras clave}

Comercio informal; Crisis económica; Migración maliense; Movilidad.

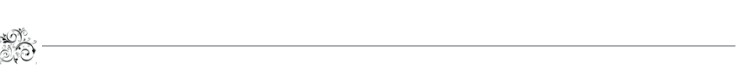

\section{TITLE}

Recipes for the crisis: the transnational mobility of Malian informal trade companies

\section{Abstract}

Expelled out of the country workforce, as a consequence of the economic crisis, many Malian migrants in Spain explore today used goods trade opportunities between Spain and their home countries. They form micro-enterprises that profit from a growing demand of cheap European used goods in Africa. These micro-enterprises have positive and negative effects; on one side, they capitalize in Africa the potentiality of discarded goods in Europe, on the other side, they also create new environmental issues, due to the lack of facilities able to treat the recycling of such goods at the end of their second life. The article also approaches these initiatives in order to point out migrants' ability to redraw their migration projects affected by job insecurity.

\section{KEYWORDS}

Informal trade; Economic crisis; Malian migration; Mobility. 


\section{ntroducción}

Afectados por la erosión del mercado del trabajo por cuenta ajena y por el desplome de sectores de actividad como él de la construcción, que alimentaron el crecimiento de la economía española hasta el año 2008, muchos migrantes africanos han vivido en los últimos años situaciones de precariedad y riesgo socioeconómico. Una salida para algunos de ellos ha sido una nueva emigración hacia Francia, Inglaterra o Alemania, países cuyos mercados del trabajo se presentan más dinámicos que el español. Otros migrantes, han intentado reciclarse en la agricultura, aunque se trate de un sector sujeto hoy a cierta saturación, debido a la llegada masiva de mano de obra procedente de otros ámbitos. Han aumentado al mismo tiempo los migrantes africanos que deciden dedicarse al comercio de productos de ocasión con sus países de origen. De esta forma, capitalizan el potencial económico del único recurso estratégico que les diferencia de los trabajadores españoles, generalmente más formados y mejor posicionados frente a la crisis: su disponibilidad para el movimiento. En otras palabras, para muchos africanos la movilidad se ha convertido en un recurso clave.

En este artículo se tratará el caso de los migrantes malienses residentes en España involucrados en actividades transnacionales de comercio de ocasión con Mali. El objetivo del análisis será comprender el funcionamiento de este modelo de negocio, las potencialidades y fragilidades de estas empresas y, asimismo, las dinámicas de inclusión y exclusión de las mismas en el tejido económico local en España y en Mali. Como intentaré demonstrar, estas actividades explotan, por una parte, ciertas contradicciones del sistema de producción industrial en Europa y, por otra, el aumento del consumo privado en África y la abundante demanda, en países como Mali, de bienes procedentes de Europa a precios asequibles.

Empezaré abordando el impacto y la percepción de la crisis económica en la población maliense en España y su creciente vinculación con negocios relacionados con el sector de lo usado: el auge de este comercio refleja un momento de crisis de acceso al empleo para los malienses en España, y es para muchos una de las pocas formas de reciclaje profesional y personal a su alcance. Trataré a continuación las características de estos negocios, las vías de suministro y los espacios donde se realizan tanto en Europa, como en África. Resulta interesante detenerse en los aspectos ambivalentes de estas actividades, disimuladas en Europa y muy visibles en África, objeto de sentimientos contradictorios por parte de los actores involucrados. Concretamente, en la última parte del artículo se abordarán las oscilaciones inherentes al estatus de estas actividades desde la perspectiva de quien participa en ellas: en los relatos de estas aventuras comerciales, en las crónicas de picaresca de estos viajes y en las quejas de estos comerciantes se aprecia una combinación de sentimientos diferentes. Por un lado, ganas de rescate, ambición, apetito empresarial, y, por el otro, sensación de precariedad e incluso vergüenza por dedicarse a un sector que muchos relacionan con los trapicheos y las rebuscallas. En este sentido, las trayectorias de estas personas nos cuentan la efervescencia, el ingenio, pero también la fragilidad de un mundo flotante constantemente en busca de nuevos equilibrios frente a una crisis sistémica, que ha perturbado los proyectos de vida de una entera generación de migrantes.

De manera trasversal, este artículo quiere señalar la importancia de formular una reflexión sobre algunas de las consecuencias menos evidentes de la crisis económica española: en particular, su impacto en el contexto socioeconómico y medioambiental de otros países. 
En Mali, la proliferación de microempresas de comercio de productos usados gestionadas por migrantes desempleados en busca de una nueva fuente de ingresos transfigura el comercio local, además de suponer un riesgo para el medio ambiente: de hecho, el traslado masivo de viejos electrodomésticos (en algunos casos dotados de sistemas de funcionamiento obsoletos y contaminantes), vehículos de ocasión, piezas de recambio para coches y otros enseres desechados a un país con escasa o nula capacidad para tratar residuos peligrosos es un problema potencial cuyas implicaciones quedan por evaluar.

Este análisis se basa en una metodología de investigación prevalentemente cualitativa: a partir de un trabajo etnográfico multi-situado ${ }^{1}$ dirigido a comprender las estrategias de reacción a la crisis de los migrantes malienses y su movilidad geográfica, se han reconstruido los itinerarios biográficos de 55 malienses residentes en España. El material etnográfico recolectado se basa en 63 entrevistas individuales no dirigidas, 7 entrevistas colectivas y un ejercicio de observación participante en Madrid, Paris, Albacete y Bamako. Los 55 migrantes seleccionados para el estudio intentan reflejar la repartición por sexo y edad del conjunto de la población identificada, un colectivo bastante joven y en su mayoría de sexo masculino²: se han entrevistado (en algunos casos más de una vez a lo largo del tiempo para tener una perspectiva longitudinal) a 9 mujeres y a 46 hombre de edad comprendida entre los veintidós y los cincuenta y seis años, todos ellos llegados a España entre 1997 y 2010. Las entrevistas han sido realizadas principalmente entre enero y julio de 2014, habiéndose llevado a cabo una serie de entrevistas previas para seleccionar la muestra de encuestados en 2011 y 2013.

La mayoría de las entrevistas se han llevado a cabo entre Madrid (23) y Bamako (18), aunque se hayan identificados otros espacios de observación (París y Albacete) relevantes para estudiar diferentes tipas de movilidad geográfica: en concreto, la re-migración hacia otras capitales europeas y el éxodo rural de malienses anteriormente residentes en las ciudades españolas. En todo caso, el lugar de realización de las entrevistas no corresponde necesariamente al lugar de residencia o de instalación de los encuestados: en muchas ocasiones no es más que una etapa en un itinerario complejo.

\section{Los malienses, la crisis y el auge del sector del comercio de bienes de ocasión}

Los ciudadanos de Mali en España constituyen una comunidad relativamente pequeña (23 175 personas según datos del Instituto Nacional de Estadística actualizados al primer trimestre de 2017). Sin embargo, su presencia ha conocido un incremento espectacular a partir del año 2000, multiplicándose casi por diez en razón de ocho años: se ha pasado de 2320 presencias del año 2001 a 22860 del 20093. Esta población ha llegado a España atraída por las condiciones favorables que la economía española presentaba a principio de la década del $2000^{4}$, incorporándose al

\footnotetext{
1 MARCUS, George E., "Ethnography In/Of the World System: the Emergence of Multi-Sited Ethnography" en Annual Review of Anthropology, nO24, 1995, pp. 95-117; RIVERO, Patricia J., "La investigación multilocalizada en los estudios migratorios transnacionales. Aportes teóricos y prácticos" en Trabajo y Sociedad, no 28, 2017, pp.327-342.

2 FUNDACIÓN CEIMIGRA, "Nuevos Ciudadanos de Mali en España", Miradas desde la migraciones, 2010, http:// www.ceimigra.net/observatorio/images/stories/mirada_mali_vfb.pdf [Consultado el 27 de agosto de 2017]

3 Ibídem.

4 COLECTIVO IOE, "La población inmigrada ante la crisis: ¿mirando hacia otro lado?", 2013, https://www. colectivoioe.org/uploads/0e22cdc4cf3eebeac22b81ad7ac32062f9cf9cf4.pdf [Consultado el 27 de agosto de 2017]
} 
mercado del trabajo principalmente en el sector de la construcción y de la industria.

La improvisada desaceleración de estos sectores ha planteado un reto para la mayoría de estas personas, al igual que para el conjunto de la población migrante ${ }^{5}$. Muchos de ellos han perdido sus empleos, en ocasiones sus casas ${ }^{6}$. Al cerrar o al restructurar drásticamente su plantilla, las empresas de construcción han contribuido a la creación de un paro estructural entre una población con un nivel de instrucción muy bajo y poco formada en otros sectores que no fueran aquellos en que habían sido empleados. Según datos de las oficinas de empleo ${ }^{7}$, los malienses desempleados han aumentado mucho en pocos años, pasando de ser 2200 en 2008 (es decir el 15\% del total de la populación activa maliense) a ser 9000 en 2011 (el $48 \%)$.

Este aumento pone de manifiesto la situación crítica de este colectivo en los años posteriores a la última crisis. La rapidez inusitada de la transformación del mercado del trabajo, así como la percepción de un agotamiento repentino de las oportunidades de empleo, son elementos que marcan las entrevistas de casi todos los malienses encuestados, como demuestran las palabras de Abdoulaye $^{8}$ (cuarenta y nuevo años, padre de familia, llegado a España en 1998, obrero especializado ahora en paro) y de Mohamed (treinta y dos años, soltero, Ilegado a España en 2002, ha trabajado en la agricultura y en diferentes obras civiles):

\begin{abstract}
"Nadie imaginaba que la crisis iba a llegar tan profundo. En 2007, con todo el trabajo que había en España y ahora... ifíjate! iEn 2007 mi empresa buscaba a gente y no encontraba! La mía era una empresa internacional y ahora la fábrica ha cerrado. Tú imagínate la cosa como está ahora. Siempre pasa esto, sin pensar las consecuencias, la inmigración te atrapa. Y ahora, estamos atrapados"9.

"iEsto no puede ser! iEn un solo año, no hay trabajo en ningún lado! Sabes, la mayoría de nosotros, la gente estaba trabajando en la construcción. Ahora en las casas que hemos hecho, ya no hay nadie, la gente no tiene dinero para pagar. ¿El dinero que han ganado con las casas, dónde está? ¿Ahora nadie está trabajando, dónde está el dinero?"10.
\end{abstract}

Estos pocos ejemplos revelan la incredulidad que ha acompañado esta brusca inversión

5 LÓPEZ-SALA, Ana María y OSO, Laura, "Inmigración en tiempos de crisis: dinámicas de movilidad emergentes y nuevos impactos sociales" en Migraciones, n³7, 2015, pp. 9-27; ROGERS, Ali, Recession, Vulnerable Workers and Immigration. Compass, Oxford, 2009.

6 Desde el comienzo de la crisis, han aumentado enormemente los desahucios y las expulsiones de pisos alquilados que afectan a personas migrantes (HUMAN RIGHTS WATCH, "Sueños rotos. El impacto de la crisis española de la vivienda en grupos vulnerables", mayo de 2014: http://www.solidarios.org.es/wp-content/uploads/suenosrotos-impacto-de-la-crisisen-vivienda.pdf [Consultado el 27 de agosto de 2017]).

7 Los datos relativos a la situación laboral de los ciudadanos malienses han sido elaborados a partir de una solicitud de información dirigida al Instituto Nacional de Estadística (INE), en el marco de la implementación de un proyecto de codesarrollo con Mali llevado a cabo por la ONG Movimiento por la paz, el Desarme y la libertad, proyecto con él que he colaborado en el año 2011.

8 El nombre de Abdoulaye, como él de los otros malienses citados en el artículo, son nombres ficticios para proteger el anonimato de los encuestados.

9 Entrevista con Abdoulaye, realizada en Madrid el 31/01/2014.

${ }^{10}$ Entrevista con Mohamed, realizada en Madrid el 12/03/2014. 
de tendencia de la economía española. Abdoulaye y Mohamed evocan los principales elementos de este nuevo paisaje: empresas bien posicionadas en el mercado cierran sus puertas, el empleo se destruye a un ritmo inquietante, el sector inmobiliario se paraliza y el poder de adquisición de las clases medias y bajas cae en picado.

Para muchos, el comercio de productos de ocasión pasa a ser considerado una salida profesional muy interesante $y$, sobre todo, al alcance de cualquiera que disponga de un permiso de conducir y de un pequeño capital de inversión. El modelo de negocio suele ser siempre el mismo: se trata de comprar un vehículo de ocasión en España, o en otro país europeo, ocuparse del papeleo para que el coche (o el camión) sea apto para la exportación, acondicionar el vehículo como medio de transporte para otros productos de ocasión o nuevos y emprender un viaje por carretera hasta Mali (o embarcar el coche en un barco hasta Senegal y luego conducir hasta Mali). Una vez allí, después de pagar las tasas de la aduana, no resta que vender, tanto el coche, como los bienes transportados y volver a España por avión.

Independientemente de su tamaño, experiencia o éxito, estas pequeñas empresas transnacionales tienen en común el uso estratégico de la movilidad como un recurso capitalizable. Este aspecto, al igual que el conocimiento de los códigos y espacios comerciales de dos contextos lejanos, es uno de los pocos recursos al que los migrantes acceden con ventaja respecto a las poblaciones "sedentarias" de España y Mali1

\section{Actores, productos y suministros: radiografía de un negocio de éxito}

Todo lo que se tira en Europa, aquí en Mali es dinero ${ }^{12}$.

Así es como cuenta su comienzo en este tipo de comercio Ibrahim, un maliense de cuarenta y tres años, residente en Madrid que llegó a España en 2001 y se ha empleado desde entonces en diferentes empresas de construcción:

"En 2010 la empresa para el trabajo, y yo termino en el paro. Desde allí me he lanzado a hacer negocios. Compro coches, los llevo allí [a Mali] y los vendo. Y luego rápidamente vuelvo aquí. Me quedo allí dos o tres semanas. Depende del coche, si está bueno bueno, lo vas a liquidar rápido. Y luego también por la noche voy a buscar cosas tiradas: las televisiones, la ropa, lo que sea que esté limpio, que esté bien. Las teles, los ventiladores, los pillas allí en la basura, por la noche. De día también se encuentran, pero de noche más. Me levanto a la noche especialmente para ello. A veces compro teléfonos, para vender allí... lo que pillo, cosas que funcionen. Para lo que no funcione, allí hay talleres también que lo arreglan"13.

Para los que dispongan de medios limitados, las calles de las ciudades españolas son enormes reservas de productos: colchones, electrodomésticos, muebles, pero también

\footnotetext{
11 MOROKVASIC-MULLER, Mirjana, «La mobilité transnationale comme ressource: le cas des migrants de l'Europe de l'Est" en Cultures \& Conflits, vol. 42-43, 1999, pp. 105-122.

12 Entrevista con Alpha, realizada en Bamako el 19/07/2014.

${ }^{13}$ Entrevista con Ibrahim, realizada en Madrid el 12/03/2014.
} 
ropa vieja, zapatos usados, etc. Son bienes llegados al final de su vida útil en Europa, que se pueden fácilmente rescatar, acondicionar y revender en África. En ello insiste Karim, un maliense de cincuenta y cinco años, en España desde 1997, obrero especializado en una empresa de materiales para la construcción durante diez años; hoy Karim cobra el subsidio por desempleo y a la vez se dedica a actividades informales de comercio de ocasión:

"Karim: - ¿No has visto lo que se tira a la calle? camas antiguas, cosas... Yo lo recojo, lo desmonto en el taller. Estoy todo el día dando vuelta con mi furgoneta. Ayer llegué a casa a las tres de la noche. Son muchas horas. Por la tarde, la gente mira en futbol y yo estoy en la calle [...]. Él que me ha llamado ahora es mi socio, trabaja conmigo en lo de buscar cosas y vender. No hay horario, estamos en la calle a cualquier hora a llenar esto y descargar allí"14.

A parte de las rondas por la ciudad en busca de efectos abandonados, de manera recurrente, los informantes afirman recurrir a una red articulada de actores dedicados a la recuperación de bienes de ocasión antes de que acaben en las plantas de tratamiento de residuos. De hecho, diferentes informantes afirman contar el ayuda de personas que "interceptan" estos productos y, eventualmente los recolectan y almacenan sustrayéndolos a su habitual recorrido hacia el vertedero. El mismo Karim, por ejemplo, está en contacto con un transportista del servicio de entrega de electrodomésticos de una grande superficie comercial. Al entregar los aparatos nuevos, este empleado recoge los viejos, y los desvía hacia los camiones y furgonetas de sus contactos, en lugar de hacerlos llegar a su destino en el centro de reciclaje.

"Karim: - Mi compañero con él que trabajo, mi socio, tiene un cliente que trabaja en xxx. Ellos cada día liberan muchas neveras; él lleva eso de ir a las casas a recoger las neveras antiguas.

Investigadora: - ¿Y estas neveras no deberían acabar en una planta de reciclaje?

Karim: - Normalmente deberían acabar allí [...]. Nosotros cuando llegan las cosas, tenemos un almacén aquí para llevar a nuestro país las cosas usadas. Como neveras y lavadoras, aunque las lavadoras no tienen muchos clientes. Aun así, el motor se puede aprovechar [...]. Nosotros buscamos alguien que quiera tirar todo. Nos desplazamos y recogemos todo eso y yo lo traigo aquí a mi almacén. Si, hay que desplazarse mucho"15.

Es interesante ver como existe todo un tejido de actores interviniendo en la captación, reorganización, compra-venta y transporte de productos aparentemente inservibles destinados a reincorporarse como bienes valiosos en el ciclo económico de mercados ubicados a millares de kilómetros de distancia. De hecho, este modelo de negocio está basado no solo en los diferenciales de precio de los productos comercializados, sino también en otro aspecto clave: estos emprendedores rentabilizan el desfase que existe entre la estructura productiva europea, por un lado, que apunta a reducir la vida útil de los bienes (ya que los elevados costes de reparación los excluyen rápidamente del circuito comercial) y, por el otro, la evolución de una

\footnotetext{
${ }^{14}$ Entrevista con Karim, realizada en Madrid el 12/01/2014.

15 Entrevista con Karim, realizada en Madrid el 12/01/2014.
} 
tendencia consumidora en África que se traduce hoy en una fuerte demanda de productos de consumo a precios baratos ${ }^{16}$. Se trata de una demanda escasamente cubierta por las grandes casas de importación, ya que sus precios elevados no están al alcance de las clases medias y bajas de Mali.

Otro factor clave en estos negocios son los costes limitados que suponen la reparación de electrodomésticos y vehículos en África y más particularmente en Mali, país donde la mano de obra es muy barata. Muchos informantes me hablan de la habilidad técnica de los talleres malienses, que devuelven una segunda y una tercera vida a bienes en muy mal estado. En ocasiones estas prácticas estimulan en los encuestados un discurso apologético, que exalta el trabajo de recuperación, ofreciendo una versión a la africana de las teorías del decrecimiento feliz de Serge Latouche ${ }^{17}$ : es lo que sugieren Wagané y Baba (dos comerciantes del sector encontrados en Bamako), cuyas palabras contraponen la obsolescencia programada de los bienes en Europa, al virtuosismo de anónimos garajistas y manitas africanos:

"Todo lo que viene de Europa, ise puede reparar! Un africano que deja un aparato averiado no es un africano. En Europa, si el motor está cansado, se prefiere aparcar el coche para siempre. En África, nosotros desmontamos el motor e intentamos repararlo; y si no funciona, lo desmontamos otra vez y volvemos a intentarlo. A una mala, separamos las piezas: si el motor no vale para nada, a lo mejor la transmisión está en plena forma"18.

"Nosotros aquí, ilo reparamos todo! Es un negocio (la compra-venta de productos de ocasión) que funciona bien; sobre todo si vendes cosas de calidad, aunque haya gente que lleva a Mali unos trastos inservibles; aun así, todo lo que viene de Europa, incluso la basura pillada en la calle, se vende [...]. Las cosas que la gente de Bamako no quiere, se pueden vender en los pueblos"19.

Este último fragmento de entrevista nos lleva a reflexionar sobre dos características de este comercio en Mali: por un lado, la presencia de diferentes circuitos de venta interconectados que drenan los productos de la capital a los pueblos. Como relatado por otros encuestados, el sector de lo usado alimenta en Mali una cadena de ventas y reventas, a precios cada vez más bajos, en la que se ven involucrados muchos actores locales que nunca han pisado el suelo europeo. Por otro lado, cabe destacar el apetito consumista de los malienses especialmente dirigido a los productos procedentes de Europa (volveré más adelante sobre este aspecto). Coches, neveras, ventiladores, motores, piezas de recambio para coches, material informático y también colchones, ropa usada, zapatos, bolsos y todo lo que tenga el tamaño adecuado para ser transportado en el maletero de un coche o en una furgoneta: son estos los productos estrella del negocio de lo usado.

\footnotetext{
${ }^{16}$ BREDELOUP, Sylvie y LOMBARD, Jérome, «Mort de la fripe en Afrique ou fin d'un cycle?" en Revue Tiers Monde, vol.194, no 2, 2008, pp. 391-412; PERALDI, Michel, «Aventuriers du nouveau capitalisme marchand. Essai d'anthropologie de l'éthique mercantile" en ADELKAH, Fariba, BAYART, François, Les voyages du développement. émigration, commerce, exile, Karthala, Paris, 2007, pp. 73-113.

17 LATOUCHE, Serge y HARPAGÉS, Didier, La hora del decrecimiento, Editorial Octaedro, S.L., Barcelona, 2011.

18 Entrevista con Wagané, realizada en Bamako el 21/07/2014.

${ }^{19}$ Entrevista con Baba, realizada en Bamako el 17/07/2014.
} 
En ocasiones, los enseres transportados no van destinados a la venta, ya que muchos comerciantes suelen "alquilar" parte del espacio de sus coches y furgonetas para el transporte de mercancías de sus compatriotas en España. Los ingresos fluctuantes del negocio de compra-venta se complementan, así, con ingresos más estables derivados del transporte para terceros o compra de productos por encargo. De este modo, se reduce la incertidumbre y el tamaño de la inversión necesaria para realizar un viaje, y se aprovecha una demanda permanente de sistemas low cost de expedición de bienes entre los migrantes en Europa y sus familiares en Mali. Más aún, cuando el aumento de la precariedad socioeconómica de los migrantes, y la escasez de dinero líquido para remesas, convierten una bolsa de vestidos, una nevera vieja, o una maleta cargada de material informático en una manera de contribución alternativa al envío de dinero.

Por otra parte, este mecanismo permite que se beneficien de este sector también actores cuyo acceso a la circulación geográfica se ve limitado por cuestiones de dinero, papeles o responsabilidades familiares. "Muchas personas no tienen un coche para llevar sus cosas y sin embargo tienen maletas" 20 afirma un informante. Es precisamente el caso de muchas mujeres malienses en España, cuya participación en este comercio se realiza a través de los viajes a Mali de sus compañeros, familiares y conocidos $^{21}$.

En definitiva, por su capacidad para activar un sistema de relaciones entre la componente más móvil y la componente más sedentaria de la población malienses en España y Mali, el dispositivo económico que se está intentado esbozar no puede ser entendido simplemente como una infraestructura de importación comercial. Gracias a estas vinculaciones, tanto los que se desplazan, como los que no lo hacen, parecen participar (aunque lo hagan en formas y grados diferentes) en un mismo ciclo de captación, organización y traslado de mercancías, dentro de una misma economía de la movilidad transnacional.

\section{Almacenes periféricos y domicilios privados: la cara prudente del negocio de lo usado en Europa}

Detrás del vaivén de estos migrantes africanos, que parecen protagonizar aventuras comerciales aisladas y extemporáneas, encontramos no solo un abanico de actores diversos involucrados en las actividades de almacenamiento, venta y reventa, tanto en Europa, como en Mali, sino también una serie de espacios y nodos logísticos que permiten el funcionamiento de lo que va asumiendo el aspecto de un verdadero sector comercial. Parte de mi trabajo de investigación ha consistido en la observación atenta de algunos de estos espacios: se trata, en el caso europeo, de lugares muy discretos y alejados de las miradas de la opinión pública;

\footnotetext{
${ }^{20}$ Entrevista con Daouda, realizada en Madrid el 28/01/2014.

${ }^{21}$ A propósito de la participación femenina de las malienses en el comercio de ocasión, cabe destacar un dato relevante: a pesar de los diversos impedimentos (su papel social, el cuidado de los hijos, sus escasos recursos económicos) que limitan su libertad de movimiento, las mujeres suelen tener total independencia a la hora de gestionar sus negocios comerciales. Ellas tienen sus propios contactos en Mali y su clientela (generalmente femenina). Sobre el tema véanse otros ejemplos de comercio informal de mujeres migrantes en DRIS, Nassima, Ville Mouvementée. Espace public, centralité, mémoire urbaine à Alger, L'Harmattan, Paris, 2001; SCHMOLL, Camille, «Pratiques spatiales transnationales et stratégies de mobilité des commerçantes tunisiennes" en Revue Européenne des Migrations Internationales, vol. 21, n01, 2005, pp. 131-154; MANRY, Veronique, «Trabendo au féminin: les femmes algérienne dans le commerce à la valise" en ADELKAH, Fariba y BAYART, François (Eds.), Les voyages du développement. émigration, commerce, exile, Karthala, Paris, 2007, pp.219-268; RIBAS-MATEOS, Natalia y MANRY, Veronique, Mobilités au féminin: La place des femmes dans le nouvel État du monde, Karthala, Paris, 2013.
} 
en cambio, en el caso de Mali, cabe notar la visibilidad y proliferación del comercio de lo usado en el panorama de ciudades grandes y pequeñas.

Como ya en parte comentado, los migrantes que se dedican al comercio transnacional de lo usado en España, se abastecen por diferentes canales: se va de la recolección de cosas abandonadas en la calle, a la movilización de intermediarios, mayoristas y pequeños suministradores que interceptan y concentran los bienes, para su posterior venta a los comerciantes. Se trata de un mercado en vías de expansión, cada vez mejor estructurado y todavía muy heterogéneo y volátil, donde encontramos mayoristas bien organizados, al lado de un pequeño ejército de actores sin muchos recursos. A continuación, el testimonio de Aziz, un maliense de treinta y ocho años, que complementa sus ingresos, enviando a Mali zapatos y bolsos de mujer nuevos y usados:

"Hay gente que lo está pasando mal, no sabe cómo comer, no tiene dinero para comer; ellos buscan las cosas y las llevan a otros que las compra y eso. Mis cosas las compro en Lucero, de un maliense, de una casa. Es un señor que recoge de la basura y revende. Y yo compro. Yo compro muchas cosas a cincuenta, sesenta céntimos"22.

Además de domicilios privados, existen lugares específicos que permiten el almacenaje y la reventa de grandes cuantidades de productos de ocasión. He podido observar uno de ellos, en la periferia industrial al sur de Madrid. En un área muy amplia se encuentran alineados decenas y decenas de almacenes grandes y pequeños. Se trata de un sitio difícil de encontrar si no se conoce su ubicación, disimulado entre tantos polígonos y naves. En mis visitas, siempre me ha sorprendido ver cierto bullicio comercial, incluso de domingo, en este lugar periférico algo apartado de la autopista. El movimiento de vehículos y personas es permanente entre los almacenes, organizados en algunos casos como tiendas de mayoristas, donde se puede encontrar "un poco de todo" como me cuentan algunos de los regentes, aunque también me comentan que cada uno se acaba especializando en ciertos artículos.

En mis visitas, encuentro como tenderos o clientes a otros malienses y también a ciudadanos de otros países de África: Marruecos, Costa de Marfil, Camerún, etc. En muchos casos, proceden de otros trabajos y actividades que se han derrumbado con la crisis. Incluso comerciantes involucrados en el comercio de lo usado en épocas anteriores a la crisis intensifican hoy su participación en el sector. Este "espacio discreto de la globalización", para usar una fórmula de Oliver Pliez ${ }^{23}$, es un eslabón clave en la organización de la cadena comercial y asimismo un ejemplo del estatuto ambiguo de estas actividades, que evitan cualquier tipo de "publicidad" en el espacio público español. No se busca una verdadera invisibilidad, ya que almacenar mercancías no es una actividad ilegal, pero si, cierta opacidad: la mayoría de las transacciones efectuadas aquí se realizan sin ningún tipo de trazabilidad fiscal. Además, si los dueños de los almacenes más grandes declaran a Hacienda una parte de la actividad económica que realizan en este espacio, no es el caso de los pequeños comerciantes, algunos de los cuales cobran el subsidio por desempleo.

\footnotetext{
22 Entrevista con Aziz, realizada en Madrid el 22/05/2014.

${ }^{23}$ PLIEZ, Oliver, Villes du Sahara. Urbanisation et urbanité dans le Fezzan libyen, CNRS Éditions, París, 2003, p. 25.
} 
Realizadas en entornos privados o poco visibles, no declaradas a Hacienda ${ }^{24}$, para algunos actores estas actividades no se consideran como un trabajo, sino más bien maneras de sobrellevar la precariedad, o estrategias de supervivencia a falta de otras opciones. Y eso, que la puesta en marcha de un negocio de este tipo demanda muchas más competencias, contactos y conocimientos de lo que hace suponer su apariencia improvisada y extemporánea. Lo que Alain Tarrius ${ }^{25}$ ha definido el "saber circular y saber hacer circular mercancía entre países ricos y pobres" es en realidad una forma de acumulación de capital social26 que resulta de la frecuentación de un entorno transnacional, capaz de generar y socializar de manera permanente informaciones fundamentales para el éxito de estas empresas.

En las reuniones de amigos, en las conversaciones entre compatriotas, en las llamadas a familiares y socios en Mali, es donde los comerciantes malienses dan forma a sus ideas de negocios: qué productos se venden mejor en Mali, como y donde proveerse en Europa, como conseguir una matrícula en la Dirección General de Tráfico para la exportación del vehículo, qué tipo de controles se realizan a la frontera, las limitaciones a la exportación de lo usado actualmente en vigor, los procedimientos y tarifas aduaneros, la manera de lidiar con los policías que piden pagos abusivos a lo largo del camino en Marruecos y Mauritania, etc. En sus trabajos sobre el comercio informal en el Mediterráneo, Michel Peraldi ${ }^{27}$ ha empleado la noción de place marchande (o sea, plaza mercantil) para señalar no tanto un lugar físico, sino aquellos mecanismos de conexión que posibilitan el flujo transnacional de bienes consumibles entre mercados locales a gran distancia. Este flujo sería irrealizable sin la puesta en circulación de un enorme volumen de información valiosa:

"La plaza mercantil reactiva el ciclo de las mercancías cuyo destino se suponía terminado según las reglas del mercado mundial, es el caso de los productos de ocasión que las normas y los gustos del consumo occidental condenan a ser desechados. [...] La plaza mercantil se presenta entonces como un complejo económico que articula un enorme potencial de informaciones disponibles y pertinentes sobre los lugares, los stocks y sus momentos de disponibilidad con unas habilidades y competencias que posibilitan la reactivación de estos

${ }^{24}$ Hay que aclarar que no se trata en ningún caso de contrabando, ya que los comerciantes cumplen toda la normativa de Tráfico relativa a la exportación de vehículos en España, así como la burocracia en los pasajes fronterizos y los derechos de aduana en Mali.

25 TARRIUS, Alain, La mondialisation par le bas: les nouveaux nomades de l'économie souterraine, Balland, Paris, 2002, p. 51.

${ }^{26}$ Definido por Pierre Bourdieu como "el conjunto de los recursos actuales o potenciales, relacionadas con la posesión de una red durable de relaciones, más o menos institucionalizadas, de mutuo conocimiento y mutuo reconocimiento", el capital social es una de esas nociones sociológicas que ha trascendido más allá de la comunidad académica, para entrar en el lenguaje común (PORTES, Alejandro, "Capital social: sus orígenes y aplicaciones en la sociología moderna" en PORTES Alejandro, Sociología económica de las migraciones internacionales. Anthropos, Barcelona, 2012, pp. 83-100). Tan popular como controvertido, para algunos autores, hablar de capital social significa asignar un valor clave a la capacidad de los individuos para movilizar y aprovecharse de las redes sociales en las que participa (BOURDIEU, Pierre, "Le capital social" en Actes de la Recherche en Sciences Sociales, no 31, 1980, pp. 2-3); para otros, significa considerar la suma de las redes y alianzas como elemento provechoso para las colectividades (COLEMAN, James S., "Social capital in the creation of human capital" en American Journal of Sociology, no 94, 1988, pp. 95-121; PUTNAM, Robert, "Bowling Alone: America's Declining Social Capital" en Journal of Democracy, vol.6, n¹, 1995, pp. 65-78). no almacenes, coches en ruta y mercados improvisadosan recurrir uchos migrantes instalados en Europa una situacio s estrella de

27 PERALDI, Michel, «Aventuriers du nouveau capitalisme marchand. Essai d'anthropologie de l'éthique mercantile" en ADELKAH, Fariba, BAYART, François, Les voyages du développement. émigration, commerce, exile, Karthala, Paris, 2007, p. 100. 
ciclos interrumpidos de bienes"28 .

\section{La fiebre de lo usado en Bamako y su proliferación en el espacio urbano}

Al llegar a Mali, "la reactivación de estos ciclos" productivos asume un semblante mucho menos discreto que en Europa. En la capital maliense el comercio de ocasión forma parte integrante del paisaje urbano. Bajo la apelación de casses, los productos se segunda mano se venden en cualquier esquina: en mercados, en tiendas especializadas, en garajes, pero también en puestos de venta improvisados en las aceras o dondequiera que se pare un coche procedente de Europa cargado hasta el techo. Aunque haya barrios concretos donde se concentre la venta de algunos artículos como los motores o los repuestos de principales coches importados en Mali (Mercedes, Peugeot, Toyota, Nissan); sin embargo, nos encontramos con un efecto de diseminación (de "invasión" según algunos) en el espacio urbano. Hoy en Bamako, no es nada raro ver cómo cuaja una pequeña muchedumbre de compradores frenéticos detrás de una furgoneta con las puertas traseras abiertas de par en par para despachar sus mercancías recién llegadas de Europa. Esta escena produce el efecto de un imán sobre la clientela maliense, persuadida que los primeros tienen acceso a las mejores gangas. "Es un poco la anarquía, cada cual puede instalarse donde quiere para vender sus cosas" ${ }^{\prime 29}$ comenta un informante en Bamako. Y es imposible no darse cuenta de la debilidad de los malienses por los productos de ocasión, que representan para ellos una manera de apropiarse de los códigos de consumo de lo que es, en su imaginario, el Occidente próspero y moderno.

"Ahora mismo hay muchos que venden, pero también hay muchísimos que compran" admite un comerciante encontrado en Bamako. "Los malienses quieren los casses, los adoran, porque siguen siendo productos de calidad a pesar de ser usados" ${ }^{\prime \prime 30}$.

El común denominador del popurrí de productos vendidos es su procedencia europea, una procedencia que todo vendedor se esmera en anunciar sin tregua a sus clientes, como si fuera un sello de calidad. Esta referencia alcanza, en ocasiones, un matiz paradójico cuando en las etiquetas de cierta ropa usada se lee claramente la inscripción "Made in China". Hay que decir que los comerciantes (como sus clientes) hacen más bien referencia al estándar de calidad de los productos disponibles en el mercado europeo, que a su lugar de fabricación. La fórmula "viene de Europa", que se escucha constantemente en los puestos de venta de lo usado, es a pesar de todo una garantía, a la que se atribuye más importancia que a las etiquetas. Además, como bien saben muchos informantes, en la profusión oceánica de la producción china, existen mecanismos de fraccionamiento de los productos según su destino: lo que va destinado al mercado europeo debería ser de calidad superior a lo que llega en los mercados orientales o africanos, eso sin contar que los productos "Made in China" que se encuentran en Europa son a menudos seleccionados por casas conocidas que aplican un control minucioso sobre su producción deslocalizada.

Más allá de estas consideraciones, me parece interesante señalar que la buena reputación atribuida a los productos procedentes de Europa radica, asimismo, en una tradición

\footnotetext{
${ }^{28}$ Ibídem.

${ }^{29}$ Entrevista con Hussein, realizada en Bamako el 18/07/2014.

${ }^{30}$ Entrevista con Harouna, realizada en Bamako el 21/07/2014.
} 
de importación de mercancías de ocasión que se remonta a los años sesenta. "Al principio era la maleta de los inmigrantes", afirma Nassima Dris ${ }^{31}$ a propósito del caso argelino. Al igual que en los otros ejemplos de comercio de ocasión entre Europa y África analizados por diferentes autores $^{32}$, la historia del mercado de casses en Mali está indisolublemente vinculada a la experiencia de los migrantes en Europa.

Los comienzos de estas empresas comerciales se sitúan en las prácticas ostentadoras de los primeros emigrantes en los años sesenta y setenta, que volvían de Francia cargados de bienes con los que querían manifestar su éxito. Bienes que las familias se encargaban de vender, alimentando los mercados locales de ciudades grandes y pequeñas. Con el paso del tiempo, al incrementarse este flujo de productos, empieza a darse un fenómeno de progresiva transformación del sector, que ya no es la prerrogativa de los migrantes. Un grupo de comerciantes malienses invierte en él y logra reorganizar y concentrar en sus manos buena parte de las transacciones, especialmente en lo que respecta a la importación de vehículos y de textil usado ${ }^{33}$. En las últimas dos décadas se asiste a una inversión de tendencia, producida por la llegada de una gran cantidad de pequeños actores: se trata en su mayoría de migrantes malienses de Francia y España, muchos de los cuales, desempleados o en situaciones de grave precariedad en Europa, se han visto empujados a utilizar su permiso Schengen para buscarse un hueco en un mercado en vía de saturación.

"Ahora la gente se ha lanzado en masa, el mercado en Mali está inundado!" comenta un informante en Bamako "y eso tiene también efectos peligrosos porque ya no se sabe de dónde vienen los casses: puede venir de basureros. Actualmente las cosas del hogar, los colchones, los vestidos pueden traer problemas a las familias: hace poco ha habido un problema en Bamako con los chinches de los colchones usados".

La inquietud de este informante sobre la "inundación" del mercado maliense, recalca los mensajes alarmistas vertidos por la prensa en Mali34. Algunos articulistas mencionan la "proliferación incontrolada" y el "peligro para la salud pública" mientras que otros condenan la falta de voluntad política, al no haber límites fijados a la importación: Mali ha firmado sin ratificarlas (y sin darle alguna aplicación) numerosas convenciones internacionales sobre el transporte, la venta y el tratamiento de mercancías contaminantes. Por otra parte, hay quien

${ }^{31}$ DRIS, Nassima, Ville Mouvementée. Espace public, centralité, mémoire urbaine à Alger, L'Harmattan, Paris, 2001, p. 277.

32 PERALDI, Michel, Cabas et containers. Activités marchandes informelles et réseaux migrants transfrontaliers, Maisonneuve \& Larose, Paris, 2001; MANRY, Veronique, «Trabendo au féminin: les femmes algérienne dans le commerce à la valise" en ADELKAH, Fariba y BAYART, François (Eds.), Les voyages du développement. émigration, commerce, exile, Karthala, Paris, 2007, pp.219-268; SCHMOLL, Camille, «Pratiques spatiales transnationales et stratégies de mobilité des commerçantes tunisiennes" en Revue Européenne des Migrations Internationales, vol. 21, n01, 2005, pp. 131-154; STREIFF-FÉNART, Jocelyne y POUTIGNAT, Philippe, «De I'aventurier au commerçant transnational, trajectoires croisées et lieux intermédiaires à Nouadhibou (Mauritanie)" en Cahiers de la Méditerranée, n073, 2006, pp. 129-149.

33 BREDELOUP, Sylvie y LOMBARD, Jérome, «Mort de la fripe en Afrique ou fin d'un cycle?" en Revue Tiers Monde, vol.194, no 2, 2008, pp. 391-412.

${ }^{34}$ NIANGALY, Lassina, «Importation de marchandises d'occasion: Bamako, une poubelle à ciel ouvert !", Maliweb, noviembre de 2014: http://maliactu.net/mali-friperie-ou-casse-boutique-un-mal-necessaire-pour-nospopulations/ [Consultado el 27 de agosto de 2017] ; DIALLO, Omar, «Commerce d'articles de casse : Attention danger !" en L'Essor, 7 de marzo de 2014, p. 10; B.C., «Mali: Friperie ou casse-boutique: Un mal nécessaire pour nos populations!", MaliActu. noviembre de 2014 http://maliactu.net/mali-friperie-ou-casse-boutique-unmal-necessaire-pour-nos-populations/ [Consultado el 27 de agosto de 2017]. 
resalta la importancia de este mercado para los "pequeños bolsillos".

Bien sean tibiamente permisivos, o tajantemente polémicos, los mensajes de la presa canalizan una aprensión compartida por una parte de la opinión pública en Mali. Su discurso señala una consecuencia incontrovertible del incremento del flujo de mercancías de ocasión: el riesgo medioambiental que supone la llegada masiva de bienes consumibles, bienes que acabaran tarde o temprano en un vertedero en un país sin infraestructuras adecuadas para el tratamiento de residuos. "Con la importación desenfrenada de artículos de casses, ¿Mali se ha convertido en un país-vertedero?" es la pregunta provocativa del autor de un artículo publicado en el periódico maliense L'Essor el 7 de marzo de 2014³. En el artículo se citan datos que nos dan una idea del tamaño del problema: respecto a la importación de textil usado se habla de una importación en 2008 de 8384 toneladas por un valor de mercado estimado a más de 3 155 millones di F CFA (equivalente a 4809795 euros); con una progresión constante año tras año, en 2012 llegamos a un volumen de importación de 12025 toneladas por un valor de 5221 millones di F CFA (7 959411 euros). Asimismo, los articulistas señalan los efectos negativos de este incremento sobre el comercio local, afectado por la fuerte competencia y la presión a la baja sobre los precios de venta.

Sin embargo, queda por evaluar y medir atentamente el impacto de estas actividades en el tejido comercial, y en general, en la economía maliense tanto a nivel de los hogares como a nivel macro. Sin duda, se trata de un fenómeno estrechamente vinculado con otras cuestiones como el envío de remesas y la participación de los migrantes en la economía maliense.

\section{Representaciones y auto-representaciones}

Todos estos factores sitúan las actividades de comercio de ocasión en el centro de discursos enfrentados. Su estatuto es incierto y sujeto a oscilaciones: si bien, por un lado, gozan de la consideración positiva del auto-emprendimiento y del prestigio de los negocios, por el otro, la procedencia de la mercancía constituye un motivo de vergüenza, para algunos migrantes malienses.

Y eso se debe a su cercanía, en el imaginario colectivo, con el mundo de la pobreza y de la marginalidad: la manipulación y reventa de materiales destinados al vertedero, así como la recolección de objetos desechados, siguen siendo objeto de cierta estigmatización tanto en Mali como en Europa. Estas actividades, aquí como allá, evocan una relación más o menos explícita con la indigencia. Así, los encuestados alegan, en un momento dado, el potencial económico del sector de lo usado y sus oportunidades, al alcance de cualquiera que tenga habilidad y espíritu empresarial, y también cierta desazón por tener que dedicarse a actividades desprestigiadas, donde las ganancias son limitadas. Yacuba, un maliense residente en España desde 2005 que encuentro en Bamako en su puesto de venta de electrodomésticos de ocasión, parece dejarlo bastante claro, el comercio de ocasión no es más que una salida de emergencia en un periodo de crisis:

"Yacuba: - ¿Te interesa ver como hace la gente con la basura? (se ríe) El reciclaje allí no es mi interés, hay que vivir de eso, pero estar allí recogiendo

35 DIALLO, Omar, «Commerce d'articles de casse : Attention danger !" en L'Essor, 7 de marzo de 2014, p. 10. 
colchones, cosas que no valen para nada de otros países.

Investigadora: - Tú te consideras un comerciante?

Yacuba: - No yo no me quiero considerar nada, quiero tener la posibilidad de cambiar a otra cosa, no quiero vivir así, no me gusta eso, es mierda eso. Traer mierda aquí y encima calentarte la cabeza...no...La gente que llega a tener dinero compra las cosas nuevas aquí. Cosas limpias y eso. Pero es que cada día en Europa las cosas se ponen peor"36.

Yacuba se niega a definirse comerciante por miedo a que su reputación se vincule de manera permanente al comercio de lo usado, actividad que delata hoy para muchos migrantes una situación de precariedad y la falta de un empleo estable en Europa. Otros destacan las ventajas de la autonomía laboral en comparación con sus antiguos empleos, las posibilidades de ganancia e incluso la ambición y el orgullo de querer montarse un negocio independiente. Un trabajo autónomo es visto en ocasiones como un medio para superar la explotación y las malas condiciones de trabajo que muchos han experimentado trabajando por cuenta ajena. Es lo que opina Thierno, un maliense de treinta y siete años, apasionado de motores, que decide en 2009, después de pasar por una larga lista de empleos precarios y mal remunerados, lanzarse en el comercio de coches de ocasión:

"Así que un día he pensado: en lugar de esto (un trabajo sumergido en una obra con un salario muy bajo), yo también quiero intentar montarme un negocio. Si te levantas pronto, con un poco de valor, puedes triunfar en África. Hace falta el valor de crear actividades, de ser creativos. Hay que pensárselo bien, tener buenas ideas y pues... intentar llevarlas a la práctica y luego se verá" 37 .

La voluntad de rescate frente a los altibajos de la crisis, así como las ganas de sacarle partidos a las "buenas ideas" de negocios y al "valor" individual son ingredientes claves de la auto-representación de la mayoría de los encuestados. Y, sin embargo, a pesar de la habilidad emprendedora de los individuos, el éxito de estas empresas está sujeto a unas variables difícilmente controlables: robos a lo largo de la carretera, retenciones abusivas en los puestos de fronteras en Mauritania y Marruecos, calculo equivocado de los cargos aduaneros, problemas de remanentes y mercancías vendida bajo coste. La mayoría de estas empresas no puede permitirse presupuestar mucho dinero para eventuales complicaciones o situaciones de emergencia en el viaje. De modo que, según los datos recopilados, no son pocos los que salen perdiendo, o se encuentran con sus cargamentos bloqueados en la aduana. La experiencia de la inseguridad empaña los discursos de los comerciantes más optimistas, dibujando una imagen poco alentadora del comercio de ocasión. Si dejamos de lado algunas excepciones, la mayoría de los encuestados habla de él como de una necesidad, más que de una oportunidad. "Hay quien se dedica a comprar vehículos para llevarlos a Mali y venderlos" comenta Sekou, un maliense desempleado, en España desde hace más de diez años, "Si les funciona, vuelven para acá, y compran otro vehículo. La gente ahora hace esto, pero no hay nada estable en ello. iEsto no es un futuro, esto no es nada!"38.

\footnotetext{
${ }^{36}$ Entrevista con Yacuba, realizada en Bamako el 17/7/2014.

37 Entrevista con Thierno, realizada en Madrid el 17/12/2011.

${ }^{38}$ Entrevista con Sekou, realizada en Albacete el 26/06/2014.
} 
En definitiva, si en el pasado los comerciantes transnacionales malienses han sido el ejemplo más emblemático de una clase media emergente, en busca de promoción social, hoy esta imagen positiva se ha alterado profundamente. Si miramos al comercio de lo usado, sector puntero en años anteriores, que ha acuñado las fortunas de muchos comerciantes, constatamos hoy la aparición de nuevos perfiles: las transformaciones de este sector nos cuentan las trayectorias de una generación de migrantes malienses afectados por la contracción del empleo en Europa, por la precarización social y económica, así como por la drástica reducción de las oportunidades de realización personal. Para ellos, el comercio de lo usado se vuelve el último recurso a su disposición. Un recurso controvertido que supone un riesgo considerable para los sujetos involucrados, ya que no todas estas aventuras comerciales tienen éxito (sino que en ocasiones esquilman los ahorros de muchos años de trabajo asalariado). Asimismo, supone un peligro medioambiental importante para los países africanos, incapaces de contener el flujo ( $y$ el vertido) de materiales potencialmente muy contaminantes.

\section{Conclusiones}

En el panorama de estudios sobre migración y economía observamos hoy una mayor presencia de investigaciones que abordan el potencial económico de fenómenos como la movilidad geográfica y el transnacionalismo de las personas migrantes ${ }^{39}$. El caso de estudio aquí presentado trata de contribuir al desarrollo de esta corriente, que supone un cambio de enfoque en el análisis de las actividades económica de la población migrante, rompiendo con el esquema analítico que vincula la migración a un área territorial restringida, coincidente con el perímetro de un estado (se ha hablado para ello de nacionalismo metodológico ${ }^{40}$ ).

Las experiencias de comercio transnacional de lo usado constituyen un ejemplo valioso: testimonian la importancia de abordar cuestiones como el desempleo de la población migrante, a la luz de una comprensión más atenta de sus estrategias en ámbito económico y de su capacidad para aprovecharse de recursos ubicados en un espacio geográfico enormemente amplio ${ }^{41}$. Se trata de actividades que no aparecen en las estadísticas oficiales y que son difíciles de interceptar en las oficinas de empleo y otros espacios de trabajo, debido a que su naturaleza volátil y semi-regular las apartan de la mirada de la opinión publica. Al mismo tiempo, se trata de actividades económicas que representan acciones de "resistencia desde la vulnerabilidad", tal y como las definen ${ }^{42}$. En su estudio comparativo sobre los efectos de la recesión en los migrantes latinos en España y Estados Unidos, los autores ponen de manifiesto

39 MACGAFFEY, Janet y BAZENGUISSA-GANGA, Remy, Congo-Paris: Transnational Traders on the Margins of the Law, Villiers publications, London, 2000; PORTES, Alejandro, GUARNIZO, Luis Eduardo y HALLER, William J, "Transnational Entrepreneurs: An Alternative Form of Immigrant Economic Adaptation" en American Sociological Review, vol. 67, no 2, 2009, pp. 278-298; SINATTI, Giulia, "'Mobile transmigrants' or 'unsettled returnees'? Myth of return and permanent resettlement among Senegalese migrants" en Population, Space and Place, vol.17, n02, 2011, pp.153-166; BLANCO, Cristina, Movilidad humana y diversidad social en un contexto de crisis económica internacional, Trotta, Madrid, 2014; SOLANO, Giacomo, "Transnational vs. local immigrant entrepreneurs: a literature comparative analysis of the use of personal skills and social network" en American Journal of Entrepreneurship, n०8(2), 2015, pp. 1-21.

40 WIMMER, Andreas y GLICK SCHILLER, Nina, "Methodological nationalism and beyond: nation-state building, migration and the social sciences" en Global Networks, vol.2, n04, 2002, pp. 301-334.

${ }^{41}$ GUARNIZO, Luis Eduardo, "The Economics of Transnational Living'" en International Migration Review, vol. 37, n० 3, 2003, pp. 666-699.

42 AYSA-LASTRA, María y CACHÓN, Lorenzo, "Resistencia desde la vulnerabilidad : inmigrantes latinos en España y Estados Unidos" en ARANGO, Joaquín, MAHÍA, Ramón, MOYA, David y SÁNCHEZ-MONTIJANO, Elena, (Eds.), El año de los refugiados. Anuario CIDOB de la Inmigración 2015-2016, Ed. Bellaterra, Barcelona, 2016, pp. 140163. 
la capacidad de estas personas de elaborar estrategias de reacción no convencionales con los recursos a su alcance. Del mismo modo, los malienses encuestados conforman un grupo de migrantes que ha identificado en el comercio de lo usado una salida al desempleo estructural en España, individuando un nicho de mercado de fácil acceso y con cierto potencial económico en África.

Por otra parte, la observación atenta de estos negocios apunta a una serie de transformaciones en curso: en primer lugar, se destaca la evolución del comercio de productos de ocasión, saturado por la participación masiva de pequeños actores con escasa capacidad de inversión y recursos limitados. La creciente competencia y el alto riesgo de estas aventuras comerciales inciden negativamente sobre el estatus de estos comerciantes, cuyos sistemas de abastecimientos y modus operandi les vinculan, hoy más que en el pasado, con una economía de la precariedad y de la manipulación de los residuos. En segundo lugar, observamos un cambio en la opinión publica de Mali en cuanto a la acogida de estas empresas, que tiene que ver con su "proliferación indiscriminada" en el espacio urbano ${ }^{43}$, y con sus efectos contaminantes. De momento, no parecen existir datos fiables para valorar la entidad de estos fenómenos: posiblemente un estudio del impacto en Mali, tanto en lo económico como en lo ambiental, de las empresas transnacionales promovidas por los migrantes sería un apoyo valioso a la elaboración de políticas públicas eficaces, orientadas a canalizar y minimizar las consecuencias negativas de estas prácticas económicas.

En cuanto al contexto español, es preciso considerar la investigación realizada como una contribución a un ejercicio más amplio, centrado en esbozar y entender la complejidad de las estrategias que los migrantes emprenden para reconfigurar sus proyectos migratorios afectados por la crisis. Frente a una sobrerrepresentación del retorno y de la re-emigración en las investigaciones que tratan del nexo migración-crisis ${ }^{44}$, es importante tener en cuenta que los actores construyen su abanico de respuestas a la precariedad, integrando actividades diversas, como el autoempleo informal y el comercio transnacional aquí retratados. Se trata de actividades que reinventan la relación de los migrantes con el territorio, haciendo de su movilidad geográfica y de su capacidad para conectar espacios lejanos, las claves para reconfigurar sus equilibrios sociales y económicos tanto en el país de acogida como en el de origen.

\section{Bibliografía}

AYSA-LASTRA, María y CACHÓN, Lorenzo, "Resistencia desde la vulnerabilidad : inmigrantes latinos en España y Estados Unidos" en ARANGO, Joaquín, MAHÍA, Ramón, MOYA, David y SÁNCHEZMONTIJANO, Elena, (Eds.), El año de los refugiados. Anuario CIDOB de la Inmigración 20152016, Ed. Bellaterra, Barcelona, 2016, pp. 140-163.

B.C., "Mali: Friperie ou casse-boutique: Un mal nécessaire pour nos populations!", MaliActu. noviembre de 2014 http://maliactu.net/mali-friperie-ou-casse-boutique-un-mal-necessaire-pour-nospopulations/ [Consultado el 27 de agosto de 2017]

BOURDIEU, Pierre, «Le capital social" en Actes de la Recherche en Sciences Sociales, nº 31, 1980, pp. 2-3.

BLANCO, Cristina, Movilidad humana y diversidad social en un contexto de crisis económica internacional,

${ }^{43}$ DIALLO, Omar, "Commerce d'articles de casse : Attention danger !" en L'Essor, 7 de marzo de 2014, p. 10.

${ }_{44}$ MAHÍA, Ramón, "Evolución de la inmigración en España y mercado de trabajo" en ARANGO, Joaquín, MAHÍA, Ramón, MOYA, David y SÁNCHEZ-MONTIJANO, Elena (Eds.), El año de los refugiados. Anuario CIDOB de la Inmigración 2015-2016, Ed. Bellaterra, Barcelona, 2016, pp. 107-137. 
Trotta, Madrid, 2014.

BREDELOUP, Sylvie y LOMBARD, Jérome, «Mort de la fripe en Afrique ou fin d'un cycle?" en Revue Tiers Monde, vol.194, no 2, 2008, pp. 391-412.

COLECTIVO IOE, "La población inmigrada ante la crisis: ¿mirando hacia otro lado?", 2013, https://www. colectivoioe.org/uploads/0e22cdc4cf3eebeac22b81ad7ac32062f9cf9cf4.pdf [Consultado el 27 de agosto de 2017]

COLEMAN, James S., "Social capital in the creation of human capital" en American Journal of Sociology, no 94, 1988, pp. 95-121.

DIALLO, Omar, «Commerce d'articles de casse : Attention danger !" en L'Essor, 7 de marzo de 2014, p. 10.

DRIS, Nassima, Ville Mouvementée. Espace public, centralité, mémoire urbaine à Alger, L'Harmattan, Paris, 2001.

FUNDACIÓN CEIMIGRA, "Nuevos Ciudadanos de Mali en España", Miradas desde la migraciones, 2010, http://www.ceimigra.net/observatorio/images/stories/mirada_mali_vfb.pdf [Consultado el 27 de agosto de 2017]

GUALDA, Estrella, "Migración circular en tiempos de crisis. Mujeres del Europa del Este y africanas en la agricultura de Huelva" en Papers, vol. 97, n03, 2012, pp. 613-640.

GUARNIZO, Luis Eduardo, "The Economics of Transnational Living'" en International Migration Review, vol. 37, no 3, 2003, pp. 666-699.

HUMAN RIGHTS WATCH, "Sueños rotos. El impacto de la crisis española de la vivienda en grupos vulnerables", mayo de 2014: http://www.solidarios.org.es/wp-content/uploads/suenos-rotosimpacto-de-la-crisisen-vivienda.pdf [Consultado el 27 de agosto de 2017]

LATOUCHE, Serge y HARPAGÉS, Didier, La hora del decrecimiento, Editorial Octaedro, S.L., Barcelona, 2011.

LÓPEZ-SALA, Ana María y OSO, Laura, "Inmigración en tiempos de crisis: dinámicas de movilidad emergentes y nuevos impactos sociales" en Migraciones, n037, 2015, pp. 9-27.

MAHÍA, Ramón, "Evolución de la inmigración en España y mercado de trabajo" en ARANGO, Joaquín, MAHÍA, Ramón, MOYA, David y SÁNCHEZ-MONTIJANO, Elena (Eds.), El año de los refugiados. Anuario CIDOB de la Inmigración 2015-2016, Ed. Bellaterra, Barcelona, 2016, pp. 107-137.

MANRY, Veronique, «Trabendo au féminin: les femmes algérienne dans le commerce à la valise" en ADELKAH, Fariba y BAYART, François (Eds.), Les voyages du développement. émigration, commerce, exile, Karthala, Paris, 2007, pp.219-268.

MARCUS, George E., "Ethnography In/Of the World System: The Emergence of Multi-Sited Ethnography" en Annual Review of Anthropology, n024, 1995, pp. 95-117.

MASSEY, Douglas S. y AYSA-LASTRA, Maria, "Social Capital and International Migration from Latin America" en International Journal of Population Research, vol. 2011, 2011, pp. 1-18.

MACGAFFEY, Janet y BAZENGUISSA-GANGA, Remy, Congo-Paris: Transnational Traders on the Margins of the Law, Villiers publications, London, 2000.

MOROKVASIC-MULLER, Mirjana, «La mobilité transnationale comme ressource: le cas des migrants de I'Europe de I'Est" en Cultures \& Conflits, vol. 42-43, 1999, pp. 105-122.

NIANGALY, Lassina, «Importation de marchandises d'occasion: Bamako, une poubelle à ciel ouvert !", Maliweb, noviembre de 2014: http://maliactu.net/mali-friperie-ou-casse-boutique-un-malnecessaire-pour-nos-populations/ [Consultado el 27 de agosto de 2017]

PERALDI, Michel, Cabas et containers. Activités marchandes informelles et réseaux migrants transfrontaliers, Maisonneuve \& Larose, Paris, 2001.

PERALDI, Michel, «Aventuriers du nouveau capitalisme marchand. Essai d'anthropologie de l'éthique mercantile" en ADELKAH, Fariba, BAYART, François, Les voyages du développement. émigration, commerce, exile, Karthala, Paris, 2007, pp. 73-113.

PLIEZ, Oliver, Villes du Sahara. Urbanisation et urbanité dans le Fezzan libyen, CNRS Éditions, París, 2003.

PORTES, Alejandro, "Capital social: sus orígenes y aplicaciones en la sociología moderna" en PORTES Alejandro, Sociología económica de las migraciones internacionales. Anthropos, Barcelona, 2012, pp. 83-100.

PORTES, Alejandro, GUARNIZO, Luis Eduardo y HALLER, William J, "Transnational Entrepreneurs: An Alternative Form of Immigrant Economic Adaptation" en American Sociological Review, vol. 67, no 2, 2009, pp. 278-298.

PUTNAM, Robert, "Bowling Alone: America's Declining Social Capital" en Journal of Democracy, vol.6, n01, 1995, pp. 65-78.

RIBAS-MATEOS, Natalia y MANRY, Veronique, Mobilités au féminin: La place des femmes dans le nouvel État du monde, Karthala, Paris, 2013.

RIVERO, Patricia J., "La investigación multilocalizada en los estudios migratorios transnacionales. Aportes teóricos y prácticos" en Trabajo y Sociedad, no 28, 2017, pp.327-342.

ROGERS, Ali, Recession, Vulnerable Workers and Immigration. Compass, Oxford, 2009. 
SCHMOLL, Camille, «Pratiques spatiales transnationales et stratégies de mobilité des commerçantes tunisiennes" en Revue Européenne des Migrations Internationales, vol. 21, n01, 2005, pp. 131154.

SINATTI, Giulia, "'Mobile transmigrants' or 'unsettled returnees'? Myth of return and permanent resettlement among Senegalese migrants" en Population, Space and Place, vol.17, n02, 2011, pp.153-166.

STREIFF-FÉNART, Jocelyne y POUTIGNAT, Philippe, «De l'aventurier au commerçant transnational, trajectoires croisées et lieux intermédiaires à Nouadhibou (Mauritanie)" en Cahiers de la Méditerranée, n073, 2006, pp. 129-149.

SOLANO, Giacomo, "Transnational vs. local immigrant entrepreneurs: a literature comparative analysis of the use of personal skills and social network" en American Journal of Entrepreneurship, n०8(2), 2015, pp. 1-21.

TARRIUS, Alain, La mondialisation par le bas: les nouveaux nomades de l'économie souterraine, Balland, Paris, 2002.

TORRES, Francisco y GADEA, Ma Elena, Crisis, inmigración y sociedad, Talasa, Madrid, 2015.

WIMMER, Andreas y GLICK SCHILLER, Nina, "Methodological nationalism and beyond: nation-state building, migration and the social sciences" en Global Networks, vol.2, n04, 2002, pp. 301-334. 


\section{RELACIONES INTERNACIONALES}

Revista académica cuatrimestral de publicación electrónica Grupo de Estudios de Relaciones Internacionales (GERI) Universidad Autónoma de Madrid, España

www.relacionesinternacionales.info

ISSN 1699 - 3950

ff facebook.com/RelacionesInternacionales

twitter.com/RRInternacional 